\title{
Variáveis que Influenciam a Escolha dos Estudantes por Cursos de Pós-Graduação Lato Sensu a Distância na Área de Negócios
}

\section{Resumo}

Baseando-se na Teoria da Avaliação Orientada ao Usuário de Scriven o objetivo geral deste estudo foi identificar e analisar o grau de importância atribuído por estudantes brasileiros às variáveis que os influenciam nas escolhas por cursos de pósgraduação lato sensu a distância na área de negócios. A pesquisa é classificada como descritiva e utilizou-se de questionário eletrônico para levantamento dos dados, com a participação de 354 estudantes de cursos de pós-graduação lato sensu a distância na área de negócios, de algumas localidades brasileiras. O questionário foi composto de 16 variáveis para as quais os estudantes deveriam atribuir nota de 0 a 10 . Os resultados indicaram que 04 variáveis tiveram média da nota acima de 9 , sendo a variável flexibilidade o principal fator considerado pelos respondentes na escolha de um curso EaD. Assim, fica evidente que a possibilidade de poder estruturar o curso conforme sua disponibilidade de tempo é fundamental para os estudantes. Mas, dispor de um corpo docente capacitado (2 ${ }^{\text {a }}$ variável mais influente) e de um currículo adequado às suas necessidades pedagógicas $\left(4^{\mathrm{a}}\right)$ também são características essenciais. Por fim, custo foi apontada pelos respondentes como a terceira variável mais importante. Alguns autores, inclusive, consideram-na decisiva na escolha dos estudantes em razão de os cursos $\mathrm{EaD}$ serem frequentemente mais baratos que os cursos presenciais. Verificou-se, ainda, que as mulheres atribuem maior valor às variáveis internas pesquisadas do que os homens. Além disso, constatou-se que a localização do polo de apoio é determinante para a escolha do curso.

Palavras-chave: Ensino a Distância. EaD. Pós-Graduação. MBA.

\begin{abstract}
Eduardo Mendes Nascimento Mestre em Ciências Contábeis pela UFMG e professor da Universidade Federal de Minas Gerais (UFMG). Contato: Av. Antônio Carlos, 6627, Pampulha, Belo Horizonte, MG, Brasil, CEP: 31270-901 E-mail: e.mn@uol.com.br
\end{abstract}

\section{Jacqueline Veneroso}

Alves da Cunha

Doutora em Controladoria e Contabilidade pela USP e professora da Universidade Federal de Minas Gerais (UFMG). Contato: Av. Antônio Carlos, 6627, Pampulha, Belo Horizonte, MG, Brasil, CEP: 31270-901. E-mail: jvac@face.ufmg.br

Marcia Athayde Matias

Doutora em Controladoria e Contabilidade pela USP e professora da Universidade Federal de Minas Gerais (UFMG). Contato: Av. Antônio Carlos, 6627, Pampulha, Belo Horizonte, MG, Brasil, CEP: 31270-901. E-mail: mathayde@usp.br

\section{Edgard Bruno}

Cornacchione Junior Livre docente e Doutor em Ciências Contábeis pela USP, Ph.D. em Educação pela Universidade de Illinois e Professor titular da Universidade de São Paulo. Contato: Av. Prof. Luciano Gualberto, 908, Cidade Universitária, São Paulo, SP, Brasil, CEP: 05558-010.

E-mail: edgardbc@usp.br 


\section{Introdução}

Como apelo ao substancial aumento na procura por cursos de formação superior (graduação e pós-graduação), surgiu no Brasil uma demanda social para que o acesso a esse ensino fosse democratizado, alcançando um número maior de indivíduos. Nesse contexto, o Ensino a Distância (EaD) surge como uma importante ferramenta para viabilizar essa ampliação, principalmente por se tratar de uma modalidade de ensino menos oneroso, quando comparado ao modelo tradicional e que consegue conferir maior flexibilidade ao processo de aprendizagem (Garrison, 2000; Carr-Chellman \& Duchastel, 2000; Bolliger \& Wasilik, 2009; Nichols, 2010). A democratização do ensino superior, pelo EaD, interessa à sociedade, pois faculta àqueles indivíduos afastados dos centros de referência em educação o acesso a um ensino de qualidade e com menor custo.

O Brasil possui uma extensão territorial de 8 milhões de quilômetros quadrados (Instituto Brasileiro de Geografia e Estatística [IBGE], 2011), o que o posiciona como o maior país do continente sul-americano, sendo que, em nível mundial, só é superado pela Rússia, Canadá, República Popular da China e Estados Unidos. Essa circunstância por si só serve de justificativa para que o país decida investir em EaD, com a finalidade de proporcionar ensino de qualidade a regiões que não teriam essa possibilidade devido às dificuldades geradas pela distância dos estudantes em relação aos centros de excelência em educação.

É preciso considerar, ainda, que o maior acesso aos cursos de qualidade resulta numa melhor qualificação dos gestores e também na gestão da empresa e, assim, em maior perenidade destas. Essa circunstância chama a atenção para os cursos na área de negócios que contribuem diretamente para aumentar a vitalidade das empresas, na medida em que estão vinculados à sua gestão. Dados do Serviço de Apoio às Micro e Pequenas Empresas de São Paulo [Sebrae-SP] (2010) indicam que, no Brasil, mais de 173 mil empresas foram abertas em São Paulo, sendo que $27 \%$ vão encerrar as suas atividades já no ano em que iniciaram suas atividades, de modo que, após o quinto ano, apenas $48 \%$ continuarão em operação. Assim, facultar ao estudante de Contabilidade acesso aos centros de referência em ensino de sua área de formação é permitir que mais de 32 mil concluintes desse curso, apenas em 2009 (Instituto Nacional de Estudos e Pesquisas Educacionais [INEP]. 2009) adquiram conhecimento e formação para serem aplicados nas mais de 5,1 milhões de empresas existente no Brasil (Sebrae-SP, 2010).

Assim, verifica-se aumento na procura por cursos de formação gerencial para proporcionar o desenvolvimento das capacidades estratégicas dos executivos, que enxergam nesses cursos uma alternativa para enfrentarem os desafios e as expectativas em relação a sua performance (Brandão, 2009). A busca pela diferenciação de currículo e mesmo pela evolução do desempenho profissional faz com que mundialmente sejam gastos bilhões de dólares em cursos de formação executiva para desenvolvimento do conhecimento em Administração, Contabilidade, Economia, Direito e demais áreas de conhecimento que os gestores devem dominar e que compõem a chamada business school (Ruas \& Comini, 2007).

Todavia, aqueles que desejam ingressar em um curso de pós-graduação lato sensu a distância (indivíduos, grupos ou organizações que tenham um interesse significativo na instituição ou curso) não dispõem de mecanismos hábeis para direcionarem suas escolhas. Diversamente do que ocorre com os cursos stricto sensu, que são objeto de avaliação pelo Ministério da Educação [MEC], ou mesmo com os cursos lato sensu presenciais, em relação aos quais são elaborados rankings por revistas especializadas, os cursos lato sensu a distância não possuem uma avaliação que possa orientar a escolha dos potenciais estudantes do curso.

Além disso, observa-se que a própria modalidade de ensino a distância ainda não se desenvolveu satisfatoriamente. Nesse sentido, segundo dados do MEC (2013), em 2013 havia 106 instituições no Brasil que poderiam ofertar cursos de pós-graduação lato sensu nessa modalidade o que demonstra que são poucas as instituições para ofertar os cursos.

Considerando-se os fatores elencados, evidencia-se a necessidade de facultar instrumentos para se proceder à avaliação dos cursos lato sensu a distância. Isso porque a excelência no ensino superior é definida como um elemento crítico deste, portanto os interessados têm que elaborar julgamentos sobre a es- 
colha que devem fazer (Burma, 2007; Sabir, Ahmad, Ashraf \& Ahmad 2013). O ideal é que essas decisões sejam baseadas na avaliação justa e exata dos cursos de uma instituição (Scriven, 1991; Middendorf, 2009).

Em uma avaliação de curso há muitos potenciais interessados e uma variedade de abordagens que são adequadas à situação que se pretende avaliar. Dessa forma, Scriven (1991) apresentou em 1974 um modelo chamado de Avaliação Orientada ao Usuário que faculta a usuários ou potenciais usuários medidas para análise. Tal modelo permite que, a partir do ponto de vista daqueles que estão passando pela experiência de fazer um curso ou daqueles que já vivenciaram essa experiência, tenha-se um julgamento de qualidade ou mérito a respeito do curso objeto da avaliação (Scriven, 1991).

Neste contexto e com base na Teoria da Avaliação Orientada ao Usuário fomentada por Scriven (1991), o presente trabalho buscará responder a seguinte questão de pesquisa: quais variáveis são consideradas pelos estudantes brasileiros quando optam por cursos de pós-graduação lato sensu a distância na área de negócios? Dessa maneira, o objetivo geral deste estudo é identificar o grau de importância atribuído por estudantes brasileiros às variáveis que os influenciam nas escolhas por cursos de pós-graduação lato sensu a distância na área de negócios.

Justifica-se este estudo devido à importância que os cursos de pós-graduação lato sensu na área de negócios assumiram nos últimos anos, dada sua associação com a ideia de empregabilidade e melhor desempenho das organizações. O estudo também se justifica pelo fato de a demanda por cursos a distância ter aumentado, significativamente, nos últimos anos. Assim, espera-se que a pesquisa identifique direcionadores para os indivíduos e empresas que pretendem investir em um curso nessa modalidade, considerando que seus resultados evidenciarão a percepção dos sujeitos que vivenciaram a experiência de escolher por um desses cursos e, portanto, possuem o conhecimento dos fatores que foram considerados como importantes no momento da escolha. Ou seja, o grau de importância atribuído pelos atuais estudantes de um curso $\mathrm{EaD}$ às variáveis que os influenciaram é capaz de orientar a percepção de potenciais estudantes.

Adicionalmente, o presente trabalho apresentará resultados que poderão ser capazes de, efetivamente, influenciar os estudantes quando das suas escolhas, o que permitirá que o direcionamento e a aplicação de recursos de todos os agentes envolvidos seja maximizada. Finalmente deve-se considerar que a pesquisa utilizou a metodologia de avaliação desenvolvida por Scriven, um método já validado e que também servirá para orientar outros estudos.

\section{Revisão da Literatura}

\subsection{Ensino a Distância}

As Tecnologias de Informação e Comunicação (TIC) influenciaram o progresso e a relevância que a educação a distância tem sobre a aprendizagem atualmente (Cornachione Júnior, 2004). Nas últimas décadas, observaram-se significativas melhorias na forma de oferecer o ensino a distância, considerando-se que antes essa alternativa era disponibilizada aos estudantes pelos correios ou outra forma impressa, ou mesmo por meios em que não se permitia a interação entre os agentes (estudante-professor), como é o caso do EaD pelo rádio, televisão e videocassete (Cornachione Júnior, 2004; Mantovani \& Gouvêa, 2010).

Em face da evolução das TIC, a própria definição de EaD vem sendo questionada (Belloni, 2009). Luzzi (2007) ressalta que o conceito do que seria $\mathrm{EaD}$ adapta-se às tendências de cada época, mas, numa análise longitudinal, ele foi evoluindo até culminar no que se entende hoje por essa modalidade de ensino.

A conceituação de $\mathrm{EaD}$ sofreu alterações, notadamente influenciadas pelo desenvolvimento tecnológico e de comunicação de cada período, pois de conceitos centrados em separação física de professor e estudante, passou-se a considerar a separação temporal. Observa-se essa ampliação de conceito ao verificar-se a definição contida nas leis brasileiras e mesmo nas políticas da Unesco (United Nations Educational Scientific and Cultural Organization). Para a Unesco (2002, p. 22): 
A educação a distância é qualquer processo educativo em que tudo ou a maioria do que se ensina é conduzido por alguém que está em espaço e/ou tempo diferente do estudante, de modo que toda ou a maioria da comunicação entre professores e estudantes se dá por um meio artificial, seja eletrônico ou impresso. ${ }^{1}$

O Brasil adotou a seguinte definição para EaD, presente no Art. $1^{\circ}$ do Decreto n. ${ }^{\circ} 5.622$ de 19 de dezembro de 2005, que regulamenta o Art. 80 da Lei n. 9.394 de 20 de dezembro de 1996 (Lei de Diretrizes e Bases):

[...] caracteriza-se a educação a distância como modalidade educacional na qual a mediação didático-pedagógica nos processos de ensino e aprendizagem ocorre com a utilização de meios e tecnologias de informação e comunicação, com estudantes e professores desenvolvendo atividades educativas em lugares ou tempos diversos.

Observa-se, portanto, que, na sociedade contemporânea, a conceituação de EaD passa pelos elementos: o estudante, considerado como usuário autônomo que tem capacidade de decidir sobre a aprendizagem (princípio orientador para os cursos); a utilização de materiais e recursos tecnológico-didáticos; estratégias de acompanhamento e apoio ao estudante (chats, monitoria, grupos de discussão e outros); e a divisão dos cursos em módulos, ou seja, em conteúdos curriculares de menor dimensão, passíveis de escolha pelo estudante (Belloni, 2009).

Desse modo, organismos como a Unesco recomendam que os cursos de ensino a distância sejam conceituados como open distance learning ou ensino a distância e aberto, numa tradução semântica, de modo que seja possível compreendê-los na perspectiva de uma separação física e temporal e também qualificá-los como flexíveis e mais adequados às necessidades atuais da sociedade.

\subsection{Avaliação Orientada ao Usuário}

A forma específica de uma avaliação depende da sua finalidade e público, da natureza do que é avaliado, e do contexto organizacional no qual o curso opera (LeBlanc \& Nguyen, 1997; Piercy, 2013). A avaliação facilita a tomada de decisão quando se combinam procedimentos adequados com pontos valorizados pelas partes interessadas. A seleção de variáveis para medir os instrumentos de medição, bem como a concepção de avaliação dependerão do tipo de decisões a serem tomadas (Oldfield \& Baron, 2000; Patton, 2008). Portanto, um avaliador começa com perguntas como: Qual é o propósito da avaliação? Qual é a missão da instituição? Quais são os objetivos do curso ou projeto? Quais são os resultados esperados? Quais são os critérios para o sucesso? Qual é o papel do indivíduo na instituição e quais são as competências esperadas e atributos para essa função? Que decisões precisam ser tomadas? (Poth, 2008).

Argumenta-se que o avaliador, durante uma avaliação, deve cumprir o seu papel e assumir a responsabilidade de comunicar os resultados não só a clientes, usuários e interessados, mas a todos os potenciais consumidores. Essa abordagem tem um papel importante na avaliação do ensino superior, dada a ampla gama de potenciais usuários (Middendorf, 2009). Davok (2006) sintetiza as preocupações que o avaliador deve ter durante a avaliação (planejamento e execução) e no momento de reportar os resultados. Esse autor considera que quatro aspectos devem permear o processo de avaliação: utilidade, viabilidade, propriedade e exatidão.

Uma avaliação deve ser útil, pois assim terá potencialidade de uso para os usuários (stakeholders), ou seja, terá serventia para aqueles que forem tomar conhecimento dessa avaliação. A preocupação quan-

1 "Distance education is any educational process in which all or most of the teaching is conducted by someone removed in space and/or time from the learner, with the effect that all or most of the communication between teachers and learners is through an artificial medium, either electronic or print." 
to à viabilidade de uma avaliação é necessária para que não haja interrupção do processo, de modo que o planejamento deve permitir que o processo seja totalmente exequível. O aspecto propriedade é garantido quando se resguardam os direitos individuais dos sujeitos envolvidos, como a privacidade, ou ainda quando lhes é proporcionado o devido bem-estar. O último aspecto - a exatidão - é inserido para garantir que os resultados produzidos sejam capazes de fazer conhecer os aspectos que determinam o cumprimento preciso do valor e o mérito do objeto sob avaliação (Davok, 2006), conforme apresentado nas Figuras 1 e 2.

\section{Atributo}

UTILIDADE

Garantir que a avaliação atenda às necessidades de informação dos stakeholder direta ou indiretamente envolvidos e interessados no processo avaliador.

\section{Padrões}

1 - Identificação dos Stakeholders: as pessoas envolvidas com a avaliação ou afetadas por ela devem ser devidamente identificadas, para que suas necessidades possam ser atendidas.

2 - Credibilidade do Avaliador: para que os resultados tenham o máximo de credibilidade e aceitação, as pessoas responsáveis pela avaliação devem ser confiáveis e competentes para conduzir o processo avaliador.

3 - Abrangência e Seleção da Informação: a informação coletada deve ser suficientemente abrangente de modo a tratar de questões pertinentes ao curso e dar respostas às necessidades e interesses dos clientes e dos outros stakeholders especificados.

4 - Identificação de Valores: as perspectivas, os procedimentos e a justificativa usados para interpretar as descobertas da avaliação devem ser cuidadosamente descritos, de modo a deixar bem claras as bases que sustentam os juízos de valor.

5 - Clareza dos Relatórios: os relatórios da avaliação devem descrever com clareza o curso sob avaliação e seu contexto. Devem igualmente descrever os propósitos, procedimentos e descobertas da avaliação, disponibilizando a informação essencial e tornando-a facilmente inteligível.

6 - Oportunidade e Disseminação dos Relatórios: descobertas significativas ocorridas durante o processo avaliador e os relatórios da avaliação devem ser disseminados aos usuários preferenciais, para que possam ser utilizados no momento oportuno.

7 - Impacto da Avaliação: as avaliações devem ser planejadas, conduzidas e relatadas de modo a encorajar o acompanhamento constante pelos stakeholders, tornando mais provável o uso efetivo da avaliação.

1 - Orientação para o Serviço: as avaliações devem ser projetadas de forma a ajudar as organizações a dar atendimento efetivo às necessidades de todos os que delas dependem.

2 - Acordos Formais: as obrigações das partes envolvidas no processo avaliador (o que deve ser feito, como, por quem, quando) devem ficar registradas por escrito, de modo a exigir que as partes adiram às condições do acordo ou que formalmente as renegociem. 3 - Direito dos Sujeitos: as avaliações devem ser projetadas e conduzidas de modo a respeitar e proteger os direitos e o bem-estar dos sujeitos.

4 - Interações Humanas: os avaliadores devem respeitar a dignidade e os valores

PROPRIEDADE humanos em suas interações com as pessoas associadas à avaliação, de modo a não intimidar ou magoar os participantes.

5 - Aferição Completa e Justa: a avaliação deve ser completa e justa em seu exame e registro das forças e fraquezas do curso sob avaliação, permitindo reforçar os seus pontos fortes e lidar com os seus aspectos problemáticos.

6 - Apresentação dos Resultados: as partes formalmente envolvidas na avaliação devem garantir que as pessoas afetadas por ela tenham acesso a todas as descobertas bem como as limitações pertinentes, devendo ficar assegurado a elas o direito legal de serem informadas dos resultados.

7 - Conflitos de Interesse: os conflitos de interesse devem ser discutidos abertamente e honestamente, para que eles não comprometam os processos e resultados da avaliação. 8 - Responsabilidade Fiscal: a alocação de recursos e os gastos do avaliador devem refletir procedimentos adequados e responsáveis, além de serem prudentes e éticos, para que os gastos sejam apropriados e justificáveis.

Figura 1. Atributos do Avaliador quanto a utilidade e propriedade

Fonte: Davok (2006, p. 41-42) 


\begin{tabular}{cc}
\hline Atributo & Padrões \\
\hline
\end{tabular}

VIABILIDADE de designs de avaliação de maneira que sejam operáveis em seu ambiente natural, sem desperdício de recursos no desenvolvimento da
Orientar o planejamento avaliação.

1 - Procedimentos Práticos: os procedimentos avaliativos devem ser práticos, para reduzir ao mínimo os transtornos durante a busca das informações necessárias.

2 - Viabilidade Política: a avaliação deve ser planejada e conduzida de modo a levar em conta as diferentes posições dos vários grupos de interesse, possibilitando assim obter a sua cooperação, bem como minimizar e neutralizar possíveis tentativas de algum desses grupos restringir as operações ou deturpar ou aplicar mal os resultados.

3 - Custo-Benefício: a avaliação deve ser eficiente e produzir informações suficientes e valiosas, de modo a justificar os recursos investidos.

1 - Documentação do curso: o curso sob avaliação deve ser descrito e documentado claramente e com exatidão, para que possa ser identificado com clareza.

2 - Análise Contextual: o contexto no qual o curso existe deve ser examinado detalhadamente, de modo a identificar as suas prováveis influências sobre o curso. 3 - Propósitos e Procedimentos Descritos: os propósitos e procedimentos da avaliação devem ser monitorados e descritos detalhadamente, para que possam ser identificados e aferidos.

4 - Fontes de Informação Defensáveis: as fontes de informação utilizadas na avaliação de um curso devem ser detalhadamente descritas, para que a adequação da informação possa ser aferida.

5 - Informação Válida: os procedimentos de coleta de informação devem ser escolhidos ou desenvolvidos e implementados de modo a assegurar que a interpretação final seja válida para o uso pretendido.

EXATIDÃO

Assegurar que a avaliação produza e revele informação exata e confiável sobre os aspectos que determinam o valor e o mérito do objeto sob avaliação.
6 - Informação Confiável: os procedimentos de coleta de informação devem ser escolhidos ou desenvolvidos e implementados de modo a assegurar que a informação obtida seja suficientemente confiável para o uso pretendido.

7 - Informação Sistemática: a informação coletada, processada e relatada num processo avaliador deve ser sistematicamente revisada e todos os erros devem ser corrigidos. 8 - Análise da Informação Quantitativa: a informação quantitativa em uma avaliação deve ser apropriada e sistematicamente analisada, para que as perguntas avaliativas possam ser efetivamente respondidas.

9 - Análise da Informação Qualitativa: a informação qualitativa em uma avaliação deve ser apropriada e sistematicamente analisada, para que as perguntas avaliativas possam ser efetivamente respondidas.

10 - Conclusões Justificadas: as conclusões tiradas a partir da avaliação devem ser explicitamente justificadas, para que os grupos de interesse possam aferi-las.

E11 - Relatório Imparcial: os procedimentos de relatório devem prever salvaguardas contra distorções produzidas por sentimentos pessoais e por preconceitos de alguma das partes para com a avaliação, para que os relatórios reflitam com justeza as descobertas avaliativas feitas.

E12 - Meta-avaliação: a própria avaliação deve ser avaliada formativa e somativamente, a partir destes e de outros padrões, para que a sua condução seja apropriado e uma vez concluído o processo, para que seus pontos fortes e fracos possam ser examinados minuciosamente pelos stakeholders.

Figura 2. Atributos do Avaliador quanto a viabilidade e exatidão

Fonte: Davok (2006, p. 41-42)

Assim, cada uma dessas características da avaliação permitem que ela se torne útil para os interessados. Utilidade essa que deve manifestar-se essencialmente pelo uso da avaliação em alguma decisão, permitindo ao usuário obter as informações que deseja e julga importantes. Uma avaliação ineficaz ou não utilizada não cumpre seu fim e resulta em desperdício de recurso. Nesse sentido é que deve se orientar a preocupação do avaliador.

Scriven (1991), em 1974, desenvolveu uma abordagem de avaliação chamada de Orientada ao Usuário. Esse tipo de avaliação busca fundamentalmente o ponto de vista do usuário do curso, valendo-se de sua experiência para então servir de guia aos potenciais usuários. Em estudos orientados dessa forma, o usuário torna-se um avaliador. Ele é quem pode tirar conclusões sobre um curso que está sendo avaliado, pois é quem recebe seus benefícios (Hashimoto, 2009). 
A avaliação orientada ao consumidor objetiva um levantamento com as pessoas que realmente utilizam ou utilizaram um produto ou serviço, ou seja, seu usuário, e foi desenvolvida por Scriven em 1974, sendo uma avaliação somativa. No caso de um curso de ensino, os estudantes. Conforme Scriven (1991) e Vieira (2009), ao invés de buscar estabelecer valores que atendam às necessidades dos usuários internos do curso (gestores e membros do curso), a avaliação orientada ao usuário pretende alcançar o bem-estar dos atuais e potenciais usuários do curso. "O avaliador deve identificar os resultados dos programas e seus valores sob a perspectiva das necessidades dos consumidores" (Vieira, 2009, p. 51).

Maccari (2008) afirma que, quando uma avaliação é voltada para quem utiliza o serviço, dá-se menor importância aos objetivos do curso. O ponto forte desse tipo de abordagem é a preocupação com o indivíduo e a percepção do que ele considera importante, ou seja, a sensibilidade que ele teve sobre tudo o que recebeu e qual é o valor disso para ele.

Para Scriven (1991), traçar uma avaliação de um curso na perspectiva do seu usuário é permitir que um curso seja avaliado sob a ótica da satisfação causada. O usuário vai considerar todo o investimento envolvido durante o processo, seja emocional, físico ou financeiro, e comparará com os benefícios alcançados. Portanto, será possível considerar se as necessidades dos usuários estão sendo adequadamente satisfeitas pelo curso ou mesmo quais variáveis são determinantes para a sua satisfação (Scammacca, 2003).

Nesse sentido é que é preciso identificar possíveis beneficiários da avaliação, pois ela permite aos potenciais usuários analisar, entre as alternativas disponíveis, qual proporciona maiores benefícios em termos de satisfação das suas necessidades, na medida em que disporá da análise de alguém que vivencia ou já vivenciou o curso que é objeto de seu interesse. Por essa razão, na avaliação orientada ao usuário é despendido esforço para identificar efeitos inesperados e custos ocultos, pois a avaliação torna-se um meio de informação que auxiliará na decisão de contratação de um curso por um futuro usuário (Vieira, 2009).

\subsection{Variáveis Relacionadas à Decisão dos Estudantes}

Quando uma pessoa adquire um produto, é mais objetivo para ela estabelecer padrões de qualidade e mesmo distinguir, entre dois produtos similares, qual é o melhor, ou seja, é fácil estabelecer variáveis que determinaram a escolha de um produto. Um serviço, no entanto, possui quatro características que o diferenciam das mercadorias: intangibilidade, perecibilidade, inseparabilidade da produção e consumo e heterogeneidade (Leblan \& Nguyen, 1997; Hill, 1995)

A intangibilidade decorre do fato de não ser possível materializar o serviço que é executado. A perecibilidade e inseparabilidade da produção e consumo se associam, pois dizem respeito à necessidade de um serviço ser consumido no momento que ele é prestado. Por fim, um serviço é heterogêneo, pois pode haver diversas formas de prestá-lo. Essa última característica leva a uma falta de padronização, o que significa que a qualidade do serviço pode variar consideravelmente de um prestador para outro ou, ainda, uma pessoa pode prestar duas vezes um serviço idêntico, mas com percepções de qualidade diferentes (Hill, 1995).

Também é sabido que, no momento em que um usuário vai decidir-se por um curso de ensino, ele analisa os seus atributos, integrando suas características intrínsecas e extrínsecas (Veale, 2007). Por características intrínsecas entendem-se aquelas variáveis que estão relacionadas ao curso propriamente, e que a instituição controla diretamente pela estratégia e planejamento. Por características extrínsecas ou externas, deve-se compreender aquelas que permitem que se distinga uma instituição da outra sem que haja necessidade de conhecer ambas. É o que caracteriza a instituição para o mercado (Ahmadov, 2008). De qualquer forma, um atributo, seja intrínseco ou extrínseco, será relevante quando sinalizar, predizer ou gerar benefícios importantes percebidos pelo usuário (Veale, 2007).

Portanto, quem está interessando em um curso deve, antes de contratá-lo, fazer uma opção com base em expectativas e só terá condição de avaliar se houve a completa satisfação destas, quando todo o servi- 
ço for prestado (LeBlanc \& Nguyen, 1997). Nesse sentido, diversos autores buscaram delinear medidas de qualidade, de forma a permitir uma melhor compreensão das variáveis que são relevantes para os estudantes quando estes avaliam um curso no qual estão interessados. Tais variáveis orientam as IES a adaptarem seus cursos, o que é determinante para a melhoria da qualidade do ensino ofertado, na medida em que essas variáveis correspondem às necessidades dos estudantes, de acordo com LeBlanc e Nguyen (1997).

McGorry (2003) investigou 750 estudantes de uma instituição norte-americana que oferecia cursos de MBA a distância. Os estudantes teriam que pontuar 1 quando discordassem totalmente da importância da variável e 5 quando concordassem totalmente com a importância da variável. Os itens que receberam nota acima de 3 pontos foram: contato com os colegas; facilidade de aprendizagem (em comparação com o ensino presencial); e contato com instrutores (tutores).

Johnston, Killion e Oomen (2005) buscaram o Academic Search Premier, Business Source Premier, Pre-CINAHL, CINAHL, MEDLINE, Computer Source, ERIC e outras fontes de pesquisa para fazer um levantamento bibliográfico das publicações de 1999 a 2004 que divulgaram pesquisas sobre as variáveis de satisfação dos estudantes de cursos a distância. Perceberam que as variáveis mais citadas foram: formato do curso, flexibilidade de horários, contato com o professor, contato entre os estudantes (chats, fóruns, $e$ -mails), orientação (tutores) e financiamento de equipamento de informática.

Henckell (2007) investigou 430 indivíduos norte-americanos que haviam feito pelo menos um curso a distância para saber, na visão do egresso, se o curso presencial precisa de mais ênfase em determinadas variáveis que um curso a distância ou vice-versa, ou se ambos os cursos (presenciais e a distância) precisam de idêntica ênfase nessas mesmas variáveis. A autora constatou que as variáveis que devem ter mais destaque nos cursos presenciais são: comunicação, ambiente de estudo, estilo pedagógico do professor, interação entre os estudantes. Para os cursos a distância, segundo a amostra pesquisada, a ênfase deve ser maior em: uso de tecnologia, estrutura do curso, atividades do curso, exercícios, assistência técnica, fee$d b a c k$ do professor. E, por fim, em ambos os cursos (do tipo presencial ou a distância) deve-se dar ênfase nas variáveis: preparar-se para a aula, tutor, abordagem educacional, materiais e métodos usados, organização e estrutura do curso, metodologias ativas de aprendizagem.

Penterich (2009) desenvolveu sua tese com o objetivo de investigar as competências que uma instituição de ensino deve ter para ofertar um curso de EaD. Para tanto, ele enviou um questionário a 1.476 estudantes de graduação a distância da Universidade Santo Amaro para pontuarem com conceitos (Muito Importante, Importante, Pouco Importante e Sem Importância) essas competências. As variáveis pontuadas pelos estudantes foram desenvolvidas pelo autor a partir de um referencial teórico e entrevistas feitas por meio de um questionário semiestruturado com 10 especialistas. Dessa forma, o autor descreve que os itens flexibilidade para estudar, valores das mensalidades, cursos reconhecidos pelo MEC, cursos e programas inovadores e com grades curriculares atualizadas são os que receberam o maior conceito (muito importante). Reconhecimento pelo mercado, polo de apoio presencial acessível e prestando um bom atendimento, professores com títulos (mestre e doutores), aulas via satélite com qualidade técnica (imagem, som e texto), professores tutores e funcionários técnico-administrativos bem capacitados e formados e melhor TIC receberam o conceito importante.

O MEC (2007b) produziu um trabalho recomendando as variáveis que um curso a distância deve possuir para que haja uma entrega adequada do ensino que a instituição dispõe-se a oferecer aos estudantes. Os oito itens que o MEC recomenda são: organização pedagógica adequada à modalidade de ensino, sistema de comunicação, material didático, avaliação, equipe multidisciplinar, infraestrutura de apoio, gestão acadêmico-administrativa e sustentabilidade financeira.

Na Figura 3 é apresentado um resumo das variáveis utilizadas nas pesquisas mencionadas. As variáveis foram dispostas em ordem decrescente, levando-se em conta o número de autores que as pesquisaram, tanto nos cursos presenciais como nos cursos a distância. Também é apresentada a definição operacional das variáveis a partir da definição dada pelos próprios autores. 


\begin{tabular}{|c|c|c|}
\hline Variáveis & Definição dos autores & A distância \\
\hline Currículo & $\begin{array}{l}\text { Utilidade das disciplinas para a capacitação profissional; distribuição } \\
\text { equilibrada das disciplinas e carga horária durante o curso; qualidade } \\
\text { da bibliografia utilizada; atualidade das disciplinas; equilíbrio entre } \\
\text { disciplinas teóricas e práticas. }\end{array}$ & $\begin{array}{l}\text { Johnston, Killion e } \\
\text { Oomen (2005); Henckell } \\
\text { (2007); MEC (2007b), } \\
\text { Penterich (2009) }\end{array}$ \\
\hline $\begin{array}{l}\text { Pessoal técnico- } \\
\text { administrativo }\end{array}$ & $\begin{array}{l}\text { Pessoas que podem ajudar com relação aos problemas de ordem } \\
\text { administrativa, como secretária, e ordem técnica, como o suporte técnico } \\
\text { de programas de informática, que a instituição disponibiliza. }\end{array}$ & $\begin{array}{l}\text { MEC (2007b); Henckell } \\
\text { (2007); Penterich (2009) }\end{array}$ \\
\hline Corpo docente & $\begin{array}{l}\text { Qualidade e nível das aulas; atenção, motivação, competência, } \\
\text { disponibilidade e acessibilidade dos professores. }\end{array}$ & $\begin{array}{l}\text { MEC (2007b); Penterich } \\
(2009)\end{array}$ \\
\hline Atividades & $\begin{array}{l}\text { Desenvolvimento de atividades (práticas, exemplificativas e de estudos } \\
\text { de caso) para fixação e avaliação da aprendizagem em conjunto com } \\
\text { outros colegas e individualmente. }\end{array}$ & $\begin{array}{l}\text { Henckell (2007); MEC } \\
\text { (2007b) }\end{array}$ \\
\hline $\begin{array}{l}\text { Acessibilidade às } \\
\text { instalações }\end{array}$ & $\begin{array}{l}\text { Polo de apoio presencial próximo ao estudante, para que não haja } \\
\text { necessidade de deslocamento. Disponibilidade de polos de apoio } \\
\text { descentralizados para atendimento ao estudante, com infraestrutura } \\
\text { compatível e tutores para as atividades presenciais. }\end{array}$ & Penterich (2009) \\
\hline $\begin{array}{l}\text { Uso de TIC } \\
\text { de ponta }\end{array}$ & $\begin{array}{l}\text { Utilização de ferramentas de informação e comunicação modernas, } \\
\text { avançadas e inovadoras, que possibilitem melhor interação e } \\
\text { aprendizagem. Uso de diversos tipos de TIC (síncronas e assíncronas, } \\
\text { como videoconferências, chats na internet, fax, telefones, rádio) para } \\
\text { promover a interação em tempo real entre docentes, tutores e estudantes. }\end{array}$ & $\begin{array}{l}\text { MEC (2007b); Henckell } \\
\text { (2007); Penterich (2009) }\end{array}$ \\
\hline $\begin{array}{l}\text { Metodologias } \\
\text { pedagógicas } \\
\text { utilizadas }\end{array}$ & $\begin{array}{l}\text { Utilização de metodologias adequadas ou adaptadas, se for necessário, } \\
\text { ao ambiente de aprendizagem virtual. }\end{array}$ & $\begin{array}{l}\text { McGorry (2003); } \\
\text { Henckell (2007); MEC } \\
\text { (2007b) }\end{array}$ \\
\hline $\begin{array}{l}\text { Contato com } \\
\text { professor }\end{array}$ & $\begin{array}{l}\text { Informação a respeito de como se dará o contato com o professor; } \\
\text { disponibilidade para consulta e esclarecimento de dúvidas. Informação } \\
\text { quanto ao número de horas disponíveis. }\end{array}$ & $\begin{array}{l}\text { Johnston, Killion e } \\
\text { Oomen (2005); Henckell } \\
\text { (2007) }\end{array}$ \\
\hline Tutores & $\begin{array}{l}\text { Flexibilidade no atendimento ao estudante, oferecendo horários } \\
\text { ampliados, retorno ágil das solicitações de perguntas e esclarecimentos } \\
\text { enviados; horário de atendimento presencial; incentivo e orientação } \\
\text { quanto ao desempenho no curso. }\end{array}$ & $\begin{array}{l}\text { McGorry (2003); } \\
\text { Johnston, Killion e } \\
\text { Oomen (2005); Henckell } \\
\text { (2007); Penterich (2009) }\end{array}$ \\
\hline Flexibilidade & $\begin{array}{l}\text { Horários das aulas maleáveis e adaptáveis a disponibilidade de horário } \\
\text { do estudante. }\end{array}$ & $\begin{array}{l}\text { Johnston, Killion } \\
\text { e Oomen (2005); } \\
\text { Penterich (2009) }\end{array}$ \\
\hline $\begin{array}{l}\text { Interação entre } \\
\text { os estudantes }\end{array}$ & $\begin{array}{l}\text { Incentivo à comunicação e cooperação entre os estudantes, com } \\
\text { oportunidades para o desenvolvimento de projetos compartilhados e } \\
\text { troca de informações, reconhecendo e respeitando as diferentes culturas } \\
\text { e com objetivo de construir o conhecimento; incentivo ao uso de chats, } \\
\text { fóruns, e-mail e demais formas de comunicação. }\end{array}$ & $\begin{array}{l}\text { McGorry (2003); } \\
\text { Johnston, Killion e } \\
\text { Oomen (2005) }\end{array}$ \\
\hline Custo & $\begin{array}{l}\text { Preço de matrícula; assistência financeira aos estudantes; mensalidade/ } \\
\text { custo menor. }\end{array}$ & Penterich (2009); \\
\hline
\end{tabular}

Tanto do ponto de vista da abordagem do conteúdo, quanto da forma, material didático concebido de acordo com os princípios metodológicos,

Material didático de modo a facilitar a construção do conhecimento e mediar a

Henckell (2007); MEC interlocução entre estudante e professor, devendo passar por rigoroso (2007b) processo de avaliação, visando ao seu aperfeiçoamento. ministrada a aula; participação durante a aula de forma construtiva e colegas colaborativa com intervenções oportunas, convenientes e adequadas; conclusão das atividades que foram agendadas.

\begin{tabular}{lll}
\hline $\begin{array}{l}\text { Cursos } \\
\text { reconhecidos }\end{array}$ & Cursos regularmente cadastrados, autorizados e reconhecidos pelo MEC. & Penterich (2009) \\
\hline $\begin{array}{l}\text { Sustentabilidade } \\
\text { financeira da } \\
\text { instituição }\end{array}$ & $\begin{array}{l}\text { Gestão estratégica que compreenda um planejamento quanto ao } \\
\text { investimento e custeio para garantir que haja perenidade. }\end{array}$ & MEC (2007b) \\
\hline $\begin{array}{l}\text { Financiamento } \\
\text { de equipamentos }\end{array}$ & $\begin{array}{l}\text { Possibilidade de financiamento subsidiado pela instituição de ensino ou } \\
\text { por programa de governo para aquisição de equipamentos de informática. }\end{array}$ & $\begin{array}{l}\text { Johnston, Killion e } \\
\text { Oomen (2005) }\end{array}$ \\
\hline
\end{tabular}

Figura 3. Resumo das variáveis pesquisadas 


\section{Metodologia}

O presente estudo compreende por definição uma pesquisa descritiva, pois buscou identificar e analisar a percepção dos estudantes de cursos de pós-graduação lato sensu a distância na área de negócios, considerando as variáveis que eles consideram importante na hora de se escolher o curso. Sampieri, Collado e Lucio (2006) conceituam esse tipo de pesquisa como sendo aquela que coleta variáveis de forma a ser possível verificar como é, e como se manifesta o fenômeno em análise, na medida em que busca especificar as propriedades, as qualidades e os perfis importantes de pessoas, grupos, comunidades ou qualquer outro objeto de pesquisa. Ou seja, os estudos descritivos valorizam a coleta de dados como forma de caracterizar o fenômeno pesquisado. Como método, utilizou-se a pesquisa de levantamento por meio de um questionário.

\subsection{Hipóteses}

Adicionalmente, se buscou formular hipóteses em relação ao comportamento das variáveis do estudo para serem testadas de modo imparcial. Para tanto, foram formuladas quatro hipóteses que são apresentadas e fundamentadas a seguir.

As hipóteses são as predições ou expectativas do pesquisador quanto ao modo como duas ou mais variáveis vão se relacionar. Tal expectativa pode surgir a partir de uma teoria ou de alguma especulação sobre o comportamento dessas varáveis (Gall, Gall \& Borg, 2007). Assim, não é relevante investigar de onde surge a hipótese, mas é fundamental que cada hipótese seja "acompanhada de uma justificativa que explique porque é plausível, dada a teoria de que foi derivada” (Gall, Gall \& Borg, 2007, p. 50).

- $\quad \mathbf{H}_{\mathbf{1}}$ : Mulheres atribuem maior grau de importância às variáveis internas quando comparadas aos homens.

As preferências de gênero são um dos fatores mais importantes, o que é evidenciado por estudos que demonstram que há diferença nas escolhas feitas por homens e mulheres. Nesse sentido, Michel (2010) verificou que indivíduos do gênero masculino estão atentos aos aspectos visuais, extrínsecos. Por exemplo, na escolha de um carro, os homens preferirão aquele veículo que satisfaça os desejos relacionados ao visual, ou seja, darão preferência aos atributos extrínsecos do veículo (cor, modelo, preço, status e outros), enquanto as mulheres tendem a valorizar as variáveis associadas ao desempenho e funcionalidade do veículo, ou seja, aspectos intrínsecos (desempenho, espaço, utensílios e outros) (Bailey, 1997). Dessa forma, a mulher exige praticidade, funcionalidade, aplicabilidade e desempenho, diferentemente do homem, que valoriza os aspectos visuais (Ad Hamid, 2006).

Observou-se nas pesquisas de McGorry (2003) e Henckell (2007), cuja maior parte da amostra era feminina, e nas de Ford, Joseph e Joseph (1999) e Vieira (2009), em que a amostra era majoritariamente masculina, a polarização de opiniões quando se comparam os gêneros dos indivíduos. Nas pesquisas com maioria de mulheres, os resultados demonstram que as variáveis internas, como professor, contato entre estudantes e tutor, possuem maior grau de importância (McGorry, 2003; Henckell, 2007). Nas pesquisas em que há uma prevalência de homens, as variáveis externas, como mercado de trabalho, ranking, reputação e empregabilidade, demonstraram ter maior grau de importância (Ford et al., 1999; Vieira, 2009).

- $\quad \mathbf{H}_{2}$ : Estudantes mais velhos atribuem maior grau de importância às variáveis internas em detrimento das externas quando comparados aos estudantes mais novos.

O envelhecimento causa transformações na maneira como as pessoas agem (Motta, 2009; Silva, 2009). Com o passar dos anos, os adultos amadurecem, e isso ocasiona deteriorações relacionadas aos cinco sentidos, desencadeando mudanças que afetam suas percepções e o modo pelo qual eles processam 
a informação, aprendem e tomam decisões de compra e consumo (Schein, Perin \& Sampaio, 2009). Observa-se, também, que a percepção de qualidade, à medida que a idade aumenta, é afetada também pela experiência adquirida (Carvalho, 2007). Nesse sentido, a experiência vivida confere às pessoas a capacidade de análise e comparação, o que pode determinar que elas sejam mais exigentes com alguns aspectos do que com outros quando comparadas com pessoas mais jovens (Goecking, 2006).

Burt (2000) concluiu que usuários mais jovens estão dispostos a assumir maiores riscos quando adquirem algo. $\mathrm{O}$ autor esclarece em sua pesquisa que as pessoas mais jovens privilegiam algumas vezes as variáveis associadas às características externas de um produto ou serviço em detrimento das variáveis internas.

Pode-se constatar a diferença de grau de importância dado às variáveis internas ou externas de um curso, de acordo com a idade do indivíduo, no trabalho de Vieira (2009). Essa autora verificou que existe diferença estatisticamente significativa quando se comparam os professores com os estudantes. A média de idade dos professores era de aproximadamente 47 anos, enquanto a dos estudantes, 30 .

- $\quad \mathbf{H}_{3}$ : Estudantes atribuem menor grau de importância à acessibilidade ao polo de apoio presencial em comparação às demais variáveis.

- $\quad \mathbf{H}_{4}$ : Estudantes residentes na cidade onde se localiza o polo de apoio presencial atribuem menor grau de importância a essa variável quando comparados aos outros estudantes.

O ensino a distância é uma modalidade de educação que vem sendo incentivada pelo governo e difundida nas instituições de ensino, sobremaneira nas particulares. De 2000 a 2008, o número de vagas de graduação a distância teve um crescimento de mais de 260 vezes, sendo que, dessas vagas, $85 \%$ foram disponibilizadas por IES particulares (INEP, 2010).

Entende-se que o EaD oferece ao estudante uma vantagem, quando comparado com o ensino presencial: a flexibilidade (Garrison, 2000; Carr-Chellman \& Duchastel, 2000; Bolliger \& Wasilik, 2009; Nichols, 2010). Tal vantagem refere-se também ao espaço geográfico (Granito, 2008; Comarella, 2009). Em relação ao espaço geográfico, entende-se que um estudante tem a possibilidade de escolher cursos oferecidos por instituições sediadas em localidades distantes, pois os encontros presenciais são raros e, na maioria das vezes, ocorrem em polos situados na região do estudante.

Assim, na avaliação dos estudantes de um curso a distância, a variável acessibilidade aos polos presenciais perde um pouco do grau de importância, pois esses estudantes não têm a necessidade de se deslocarem com frequência até os polos. Penterich (2009) e LeBlanc e Nguyen (1997) constataram tal evidência em suas pesquisas quando observaram que os estudantes não a achavam muito importante, atribuindo notas menores para essa variável.

\subsection{Amostra e Instrumento de Coleta de Dados}

O instrumento de coleta de dados utilizado nesta pesquisa foi o questionário, que possui a característica de atingir um maior número de pessoas simultaneamente a um custo menor, garantir o anonimato e obter várias respostas às mesmas perguntas, o que permite quantificar e comparar os resultados obtidos (Duarte \& Furtado, 2002; Gall, Gall \& Borg, 2007). Optou-se pela utilização desse instrumento por ser aquele que melhor capta a opinião ou propensão a uma atitude de um indivíduo (Sampieri et al., 2006). O meio utilizado para aplicação foi a Internet, pois, o questionário eletrônico demanda um custo menor, além de garantir o anonimato, agilidade na constituição do banco de dados e um menor número de respostas inválidas (Kiesler \& Sproull, 1986).

O questionário foi estruturado em duas partes. A primeira referente à avaliação das variáveis que mais influenciam os ingressantes na escolha de um curso a distância, na área de negócios, partindo de pesquisas empíricas, que objetivaram levantar as variáveis que podem influenciar as escolhas dos estudantes de cursos a distância, ou seja, com o mesmo objetivo ao da presente pesquisa. Assim, foram identificadas 16 
variáveis: currículo, pessoal técnico-administrativo, corpo docente, atividade, acessibilidade às instalações, uso de TIC de ponta, metodologias pedagógicas utilizadas, contato com professor, tutores, flexibilidade, interação entre os estudantes, custo, material didático, participação dos colegas, sustentabilidade financeira da instituição e financiamento de equipamentos. Foi solicitado aos respondentes dos cursos que atribuíssem uma nota de 0 (zero) a 10 (dez) às variáveis definidas, de forma que expressassem o grau de importância conferido a cada uma delas no momento em que fizeram sua escolha por um curso de pós-graduação a distância. Para captar a melhor percepção dos estudantes nas respostas aos questionários, optou-se por adotar uma escala com diferencial semântico de 11 (onze) pontos.

A segunda parte do questionário relaciona-se às questões que buscaram identificar um perfil dos respondentes. Assim, foram inseridas as seguintes variáveis: formação acadêmica, ano de nascimento, gênero, estado civil, cidade e estado onde reside, tipo de empresa em que trabalha, número de horas semanais dedicadas ao curso, se já fez outro curso de especialização e principal fonte de renda. Ao final do questionário foi deixado espaço para que os respondentes pudessem inserir comentários, caso desejassem.

Para assegurar validade, confiabilidade e comparabilidade das respostas, foi realizado um pré-teste com o instrumento. Após as entrevista cognitivas com os respondentes do pré-teste, constatou-se a necessidade de algumas adequações para o melhor entendimento do questionário.

A amostra da pesquisa configura-se como não probabilística e é constituída pelos estudantes das IES de cursos lato sensu a distância na área de negócios. Como não havia um banco de dados para definição das instituições brasileiras ofertantes desses cursos, foi feito um levantamento no cadastro on-line do MEC (2010) em 4 de maio de 2010, com a finalidade de identificar aquelas autorizadas a ofertar cursos de graduação a distância. Destaca-se que a legislação atual estabelece que IES autorizadas a ofertar um curso de graduação podem ofertar cursos lato sensu na mesma área, desde que ambos sejam oferecidos na mesma modalidade (a distância ou presencial). Isso significa que, se a instituição é autorizada a ofertar um curso de graduação em determinada área na modalidade presencial, poderá ofertar cursos lato sensu nesta área, desde que ele também seja presencial, o mesmo valendo para cursos a distância.

Foram identificados os cursos lato sensu a distância nas áreas de administração, estatística, marketing, gestão de empresas, gestão pública, gestão hospitalar, gestão de pessoas e economia. Essas especialidades são aquelas definidas pela The Association to Advance Collegiate Schools of Business como pertencentes à área de negócios (business). Foram encontrados 64 cursos de formação executiva a distância, ofertados em todo o país. Ao final do período de coleta de dados, a amostra ficou constituída pelos 361 estudantes que responderam ao questionário no período de 24 de setembro de 2010 a 28 de abril de 2011, sendo que 354 respostas foram consideradas válidas para produzir o relatório da pesquisa. Os sete questionários descartados apresentavam informações parciais, ora com respostas somente na primeira parte, ora somente na segunda, inviabilizando a análise. Inicialmente foi realizado, sobre os dados coletados, o teste de consistência interna da escala por meio do Alfa de Cronbach, que apresentou resultado de 0,9311 e para verificação da significância das diferenças de média o Teste $t$ Student, com o intuito de rejeitar ou não as hipóteses apresentadas, considerando que o teste de distribuição normal da amostra foi estatisticamente significativa, tanto pelos testes feitos de Shapiro-Wilk $(\mathrm{p}=0,0000)$ quanto pelo Shapiro-Francia $(\mathrm{p}=0,00001)$.

\section{Resultados}

Considerando os dados retornados pelos respondentes, constatou-se que os estudantes de cursos EaD de pós-graduação lato sensu na área de negócios apresentam o seguinte perfil: mulheres (60\%), casadas (47\%), remuneradas majoritariamente pelo setor público (75\%), graduadas em Administração (25\%), cursando sua primeira pós-graduação lato sensu (69\%) e com idade média de 36 anos. Esse resultado confirma o que parece ser o perfil dos estudantes dos cursos $\mathrm{EaD}$, considerando que em pesquisas anteriores eles buscavam nessa modalidade de ensino maior flexibilidade nos estudos, de modo a poderem conciliar as suas atividade do dia-a-dia com os estudos, o que pode ser verificado na Tabela 1. 
Portanto, esse resultado é indicativo de que a idade dos indivíduos que buscam um curso lato sen$s u$ a distância é maior do que a idade daqueles que cursam uma especialização lato sensu presencial, o que também pode ser confirmado com a pesquisa do INEP (2010) e os resultados da pesquisa de Vieira (2009). Em sua pesquisa, Vieira (2009) verificou que a média de idade dos estudantes de pós-graduação lato sensu presencial era de 29 anos, para os estudantes com até dois terços dos créditos concluídos, e de 31 anos, para os ingressantes. Penterich (2009) considera que os indivíduos que preferem o EaD são mais velhos que os estudantes de cursos presenciais. A possibilidade de se moldarem os horários de estudos para atender à disponibilidade de tempo, segundo o autor, é o fator determinante para aqueles que optam pelo ensino a distância, já que buscam melhorar a capacitação profissional sem necessidade de dispor de muito tempo.

A participação preponderante do gênero feminino na pesquisa parece traduzir a realidade brasileira. De acordo com INEP, em 2009, 76\% das pessoas que concluíam um curso a distância eram do sexo feminino e tinham idade média de 31 anos. Resultado próximo do encontrado por Penterich (2009), que observou que as mulheres representavam $70 \%$ dos 1.037 respondentes da sua pesquisa. Segundo o autor, a mulher é uma constante maior nos curso $\mathrm{EaD}$, pois elas procuram nesse tipo de curso a flexibilidade necessária para conciliar os estudos com as demais atividades que exercem.

Quanto à elevada participação de profissionais que possuem sua fonte de renda vinculada à alguma instituição pública (75\%), constatou-se que o Governo federal instituiu, em 2009 o Programa Nacional de Formação em Administração Pública, que busca fomentar cursos de especialização na área de gestão pública e gestão da saúde. Portanto, é de esperar-se que cursos com esse enfoque atraiam indivíduos que possuem relação econômica com o poder público. Embora a pesquisa não tenha se concentrado em algum curso específico na área de negócios, de acordo com o que a Universidade Aberta do Brasil informa em seu site, dos 269 cursos de especialização a distância cadastrados em 12 de maio de 2011, 97 eram na área de administração pública. Também, deve-se considerar que os profissionais vinculados à administração pública normalmente possuem incentivos salariais para buscarem curso de pós-graduação.

Com relação ao grau de importância atribuído pelos estudantes foi estabelecido um ranking entre as 16 variáveis da pesquisa, considerando o escore que os estudantes atribuíram a cada uma delas. Foi possível perceber que as médias das variáveis se dividem em três grupos: o primeiro, com médias de até 7,9; o segundo, com médias de 8 a 8,9; e o terceiro, com médias acima de 9 . O maior número de variáveis ficou no grupo com médias entre 8 e 8,9 ( 9 variáveis), seguido do grupo com médias acima de 9 (4 variáveis) e do grupo com médias menores que 7,9 (3 variáveis). 
Tabela 1

\section{Identificação dos Estudantes}

\begin{tabular}{|c|c|c|c|}
\hline Identificação & & Frequência & $\%$ \\
\hline \multirow{6}{*}{ Estado Civil } & Casado & 168 & $47 \%$ \\
\hline & Divorciado/Separado & 28 & $8 \%$ \\
\hline & Solteiro & 141 & $40 \%$ \\
\hline & União Estável & 16 & $5 \%$ \\
\hline & Viúvo & 1 & $0 \%$ \\
\hline & Total & 354 & $100 \%$ \\
\hline \multirow{3}{*}{ Gênero } & Feminino & 211 & $60 \%$ \\
\hline & Masculino & 143 & $40 \%$ \\
\hline & Total & 354 & $100 \%$ \\
\hline \multirow{5}{*}{ Atividade Remunerada } & Não Exerço Atividade Remunerada & 12 & $3 \%$ \\
\hline & Setor Privado & 72 & $20 \%$ \\
\hline & Setor Público & 265 & $75 \%$ \\
\hline & Terceiro Setor & 5 & $1 \%$ \\
\hline & Total & 354 & $100 \%$ \\
\hline \multirow{5}{*}{ Conclusão de Especialização Anterior } & Não & 243 & $69 \%$ \\
\hline & Sim, mas presencial & 67 & $19 \%$ \\
\hline & Sim, presencial e a distância & 14 & $4 \%$ \\
\hline & Sim, também a distância & 30 & $8 \%$ \\
\hline & Total & 354 & $100 \%$ \\
\hline \multirow{7}{*}{ Formação } & Administração & 88 & $25 \%$ \\
\hline & Ciências Contábeis & 41 & $12 \%$ \\
\hline & Direito & 51 & $14 \%$ \\
\hline & Economia & 7 & $2 \%$ \\
\hline & Engenharia & 10 & $3 \%$ \\
\hline & Outro & 157 & $44 \%$ \\
\hline & Total & 354 & $100 \%$ \\
\hline
\end{tabular}

Percebe-se pelas notas atribuídas pelos respondentes que os escores foram elevados, considerando que a variável que obteve menor escore atingiu $72 \%$ da pontuação máxima possível ( 2.808 dos 3.540 pontos possíveis), o que resultou em médias também elevadas. Apesar desse desempenho, nenhuma das variáveis obteve o escore máximo ou média 10 , sendo a maior média alcançada pela variável flexibilidade $(9,2)$. O desvio padrão e variância das notas foram baixos, significando, dessa forma, que as notas estão distribuídas em torno da média, sendo a maior diferença observada na variável financiamento de equipamentos e a menor na variável currículo. Apesar dessa pouca variabilidade, todas as variáveis receberam as notas 0 (zero) e 10 (dez).

Considerando os resultados da pesquisa, a classificação das variáveis que influenciam os estudantes brasileiros na escolha por cursos de pós-graduação lato sensu a distância, na área de negócios, de acordo com seu grau de importância, em ordem decrescente foram: ( $1^{\circ}$.) flexibilidade (nota 3.255), ( $2^{\circ}$.) corpo docente

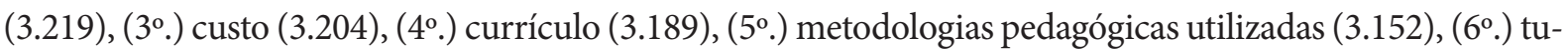
tores (3.146), $\left(7^{\circ}\right.$.) material didático (3.145), ( $8^{\circ}$.) uso de Tecnologia da Informação e Comunicação (3.122), $\left(9^{\circ}\right.$.) sustentabilidade financeira $(3.032),\left(10^{\circ}\right.$.) acessibilidade às instalações $(2.995),\left(11^{\circ}\right.$.) atividades $(2.971)$, (12 ${ }^{\circ}$.) contato com professores $(2.904),\left(13^{\circ}\right.$.) pessoal técnico administrativo (2.903), (14\% ${ }^{\circ}$ ) participação dos colegas (2.808), $\left(15^{\circ}\right.$.) interação entre estudantes (2.679) e (16 ${ }^{\circ}$.) financiamento de equipamentos (2.575). 
O fato da variável flexibilidade constar como a mais importante para os estudantes, confirma tanto os resultados encontrados por Johnston, Killion e Oomen (2005) e Penterich (2009) como o indicativo teórico de que essa é a principal vantagem dos cursos a distância (Garrison, 2000; Carr-Chellman \& Duchastel, 2000; Bolliger \&Wasilik, 2009; Nichols, 2010) Observa-se, a ainda, que os estudantes informaram no campo aberto para questões adicionais que a flexibilidade é extremamente valorizada por eles, a ponto de pedirem que não houvesse encontros presenciais: "flexibilidade para participar do curso de qualquer lugar sem a necessidade de se locomover".

Nesse sentido, um estudante sugere que haja "possibilidade de videoconferência da própria cidade, sem a necessidade de deslocamento até o polo". Também é considerada pelos estudantes a possibilidade de uma maior dilatação dos prazos de entrega das atividades: "estabelecer uma semana de prazo para a entrega dos trabalhos/atividades, (...) assim os alunos tem o final de semana para fazer as atividades". Observa-se, portanto, que alguns estudantes utilizam-se do final de semana para dedicar-se a essas atividades, o que inclusive se confirma pela reivindicação de um deles por "disponibilidade para resposta de dúvidas nos finais de semana", justificando outro estudante que isso "(...) possibilitaria maior participação dos alunos", pois “(...) a maioria trabalha". Conforme sintetizou mais um estudante: "curso a distância favorece o aluno que não tem disponibilidade de estar todos os dias na faculdade, podendo estudar em casa, nas horas vagas".

Talvez, em decorrência da extrema valorização da variável flexibilidade nos cursos $\mathrm{EaD}$, é comum o estudante desejar que não haja encontros presenciais, ainda que ele resida na mesma cidade do polo de apoio presencial. Esse desejo evidencia que, para aqueles que fazem um curso $\mathrm{EaD}$, apesar de serem poucos os encontros presenciais promovidos, seria preferível que eles não ocorressem. Cabe observar que a legislação vigente exige alguns encontros presenciais, o que parece não ser do conhecimento dos respondentes.

A variável corpo docente obteve a segunda colocação no ranking, com escore de 3.219 ( $91 \%$ do escore máximo). Era esperado que essa variável se destacasse entre as demais, devido ao número de pesquisas que a apontaram como um importante critério de escolha dos estudantes na hora de optar por um curso. Tanto em pesquisas com cursos presenciais (LeBlanc \& Nguyen, 1997; Oldfield \& Baron, 2000; Gallifa \& Batallé, 2010), quanto com cursos a distância (MEC, 2007b; Penterich, 2009) revelaram a capital importância dessa variável.

À variável corpo docente do curso a distância é dispensado tratamento diferenciado pelas pesquisas, pois, conforme o MEC (2007b), não se deve imaginar que nessa modalidade de ensino o trabalho do professor é minimizado. Ao contrário, nos cursos a distância as funções dos docentes são expandidas, o que requer que tenham qualificações que não são exigidas de professores em cursos presenciais. Em particular, o corpo docente deverá trabalhar de forma a motivar, orientar, acompanhar e avaliar os estudantes, adequando-se ao processo de ensino e aprendizagem na forma que a metodologia de ensino a distância exige (MEC, 2007b).

Em terceiro lugar, considerando o escore alcançado pelas variáveis, aparece o custo. Os respondentes atribuíram ao custo escore de 3.204 (91\% do escore máximo). Observou-se em outros estudos empíricos que o custo ora apresenta-se com um grau de importância acentuado para os estudantes, como é o caso dos resultados encontrados por Ford, Joseph e Joseph (1999), ora com grau menor, como na pesquisa de Vieira (2009).

O custo do ensino a distância é tratado por alguns autores como sendo um dos fatores que influenciam a decisão dos estudantes, pois o EaD costuma ser relativamente menos dispendioso para os estudantes (Penterich, 2009). De acordo com Nascimento (2009), esse tipo de ensino apropria-se de meios tecnológicos que permitem que os custos de desenvolvimento dos programas e a sua aplicação sejam minimizados. Além disso, conforme explica Luzzi (2007), o curso a distância é ofertado a um número maior de estudantes, permitindo à instituição maximizar os ganhos por meio do volume.

Encerrando as variáveis que tiveram média acima de 9, encontra-se a de currículo, que recebeu escore de 3.189 (90\% do escore máximo). Nos estudos já realizados sobre o tema, essa é uma das variáveis que se apresentou com maior frequência (Hill, 1995; LeBlanc \& Nguyen, 1997; Johnston, Killion \& Oomen, 2005; MEC, 2007b; Henckell, 2007; Vieira, 2009, Penterich, 2009) 
O MEC (2007b) faz considerações sobre o currículo de um curso de EaD preconizando que é por ele que se deve estruturar e organizar o curso, servindo de vínculo com o projeto pedagógico.

A organização em disciplina, módulo, tema, área, reflete a escolha feita pelos sujeitos envolvidos no projeto. A compreensão de avaliação, os instrumentos a serem utilizados, as concepções de tutor, de estudante, de professor, enfim, devem ter coerência com a opção teórico-metodológica definida no projeto pedagógico. O uso inovador da tecnologia aplicado à educação, e mais especificamente, à educação a distância deve estar apoiado em uma filosofia de aprendizagem que proporcione aos estudantes a oportunidade de interagir, de desenvolver projetos compartilhados, de reconhecer e respeitar diferentes culturas e de construir o conhecimento. (MEC, 2007b, p. 8)

Entre as variáveis que tiveram média da nota entre 8,0 e 8,9, esperava-se que duas figurassem entre os escores mais elevados, considerando os resultados anteriores encontrados por outros autores: pessoal técnico-administrativo (LeBlanc \& Nguyen, 1997; Oldfield \& Baron, 200; Gallifa \& Batallé, 2010; MEC, 2007b; Henckell, 2007; Penterich, 2009) e tutores (Mcgorry, 2003; Johnston, Killion \& Oomen, 2005; Henckell, 2007; Penterich, 2009)

A variável pessoal técnico-administrativo mostrou-se como a segunda mais recorrente nas pesquisas e demonstra ser fator determinante na satisfação dos estudantes. No entanto, pelos resultados obtidos, o escore alcançado por essa variável foi de 2.903 ( $82 \%$ do escore possível), o que a posicionou em $13^{\circ}$ lugar, ou seja, ocupou o limite inferior no grupo das variáveis com nota do segundo grupo. Essa variável apresentou especial destaque nas pesquisas anteriores, pois, conforme Oldfield e Baron (2000), devido ao contato que os estudantes mantêm constantemente com os indivíduos que lhes dão suporte, espera-se que exijam mais deles.

O escore da variável tutores foi de 3.146 (89\% do escore possível), o que a estabeleceu na sexta posição do ranking. Conforme o MEC (2007b), os tutores representam um ponto muito importante na modalidade educacional a distância, já que eles participam ativamente do processo de aprendizagem dos estudantes. Seja a distância ou nos encontros presenciais, o tutor atua e contribui para o desenvolvimento do ensino e aprendizagem e é importante para o acompanhamento e avaliação do projeto pedagógico do curso.

Reconhece-se que os estudantes atribuem um alto grau de importância à participação do tutor na sua aprendizagem. Todavia, como a interação estudante-tutor é maior por meio de mídias interativas (e-mail, chats, fóruns), essa relação pode ser afetada. Tal afirmação é ilustrada pelo comentário de um respondente, segundo o qual "os tutores a distância dão respostas muito vagas a respeito dos trabalhos exigidos no curso de pós-graduação"; e também pelo exemplo de outro estudante, que diz: "precisei de ajuda de um tutor e ele demorou a me responder e isso me fez perder o prazo. Não fiz a atividade."

\subsection{Teste das Hipóteses da Pesquisa}

Com o objetivo de testar as hipóteses sobre o comportamento das variáveis, foi realizado o Teste $t$ Student por meio do software Stata $10^{\circ}$.

Para operacionalizar os testes das hipóteses 1 e 2, foi realizada, inicialmente, a análise de componentes principais. Essa técnica consiste em "explicar a estrutura de variância e covariância de um vetor aleatório, composto de p-variáveis aleatórias, por meio da construção de combinações lineares das variáveis originais" (Mingoti, 2005, p. 59). Assim, essa técnica reduz um conjunto de variáveis a um conjunto menor, possibilitando que sejam analisadas e testadas as componentes principais daquele grupo original. Para se realizar o teste de hipótese, é escolhida aquela, ou aquelas, componente(s) que mais representa a variância dos dados originais.

A análise das componentes principais geradas para as variáveis da pesquisa, apresentada na Tabela 2 , indicou que, para as variáveis internas e externas, a componente 1 de cada grupo representa mais de $50 \%$ da variância de todos os fatores, sendo isoladamente a que tem maior representatividade. Observou-se, as- 
sim, que nenhuma outra componente obteve esse indicador tão alto ou apresentou o mesmo grau elevado de correlação entre as variáveis (considerando as variáveis internas, a correlação da componente 1 variou de 0,6567 para a flexibilidade, a 0,7973 para a variável tutores e as variáveis externas de 0,5892 para variável custo, a 0,8246 para sustentabilidade financeira da instituição ). Pelo exposto, a componente 1 , tanto das variáveis externas quanto das internas, foi a escolhida para proceder-se aos testes de diferença de média.

Tabela 2

\section{Componentes principais das variáveis}

\begin{tabular}{|c|c|c|c|c|}
\hline & & \\
\hline & & Eigenvalue & \% da Variância & $\begin{array}{c}\text { Variância } \\
\text { Acumulada }\end{array}$ \\
\hline \multirow{12}{*}{ Variáveis Internas } & Componente 1 & 6,87 & 0,5724 & 0,5724 \\
\hline & Componente 2 & 1,11 & 0,0924 & 0,6648 \\
\hline & Componente 3 & 0,66 & 0,0546 & 0,7194 \\
\hline & Componente 4 & 0,61 & 0,0508 & 0,7703 \\
\hline & Componente 5 & 0,52 & 0,0432 & 0,8135 \\
\hline & Componente 6 & 0,46 & 0,0381 & 0,8516 \\
\hline & Componente 7 & 0,39 & 0,0325 & 0,8841 \\
\hline & Componente 8 & 0,38 & 0,0315 & 0,9157 \\
\hline & Componente 9 & 0,34 & 0,0283 & 0,9439 \\
\hline & Componente 10 & 0,26 & 0,0220 & 0,9660 \\
\hline & Componente 11 & 0,23 & 0,0194 & 0,9853 \\
\hline & Componente 12 & 0,18 & 0,0147 & 1,0000 \\
\hline \multirow{4}{*}{ Variáveis Externas } & Componente 1 & 2,17 & 0,5418 & 0,5418 \\
\hline & Componente 2 & 0,79 & 0,1971 & 0,7390 \\
\hline & Componente 3 & 0,58 & 0,1461 & 0,8850 \\
\hline & Componente 4 & 0,46 & 0,1150 & 1,0000 \\
\hline
\end{tabular}

A primeira hipótese baseia-se na Teoria do Sexismo, que declara existir uma diferença comportamental entre homens e mulheres. Para a presente pesquisa, admitiu-se que mulheres valorizaram mais as variáveis internas ou intrínsecas no momento de fazer a escolha de um curso quando comparadas aos homens. Portanto, a primeira hipótese foi descrita como sendo:

- $\quad \mathbf{H}_{1}:$ Mulheres atribuem maior grau de importância às variáveis internas quando comparadas aos homens.

Utilizando-se da componente principal das variáveis internas, constatou-se que a diferença entre as médias do grupo das mulheres ( 0,57 , média gerada pela componente principal) para a média do grupo dos homens $(-0,84)$ foi de 1,4 em favor das mulheres. Os resultados do Teste $t$ Student demonstraram que a média das notas das mulheres é significativamente maior que a dos homens, firmando-se que as mulheres valorizam mais as variáveis internas dos cursos de especialização lato sensu $\mathrm{EaD}$ do que os homens $(p=0,0000)$. Portanto, a primeira hipótese da pesquisa foi confirmada, corroborando os resultados apontados por Ford, Joseph e Joseph (1999), McGorry (2003), Henckell (2007) e Vieira (2009).

A segunda hipótese se referiu à possível diferença de comportamento entre pessoas mais velhas e mais jovens, na medida em que aquelas buscariam os aspectos intrínsecos do curso, enquanto as mais novas valorizariam os extrínsecos. Assim, formulou-se a hipótese que segue:

- $\quad \mathbf{H}_{2}$ : Estudantes mais velhos atribuem maior grau de importância às variáveis internas em detrimento das externas quando comparados aos estudantes mais novos. 
Para determinação do grupo de estudantes mais velhos e do grupo dos mais novos, identificaram-se, na amostra, os estudantes com idade maior ou igual a 45 anos (mais velhos) e os estudantes com idade menor ou igual a 27 anos (mais novos). Essa distribuição foi feita levando-se em consideração a média da idade da amostra (36 anos) mais um desvio padrão (9 anos), para o grupo dos mais velhos e menos um desvio padrão, para o grupo dos mais novos. Tal procedimento foi feito considerando a distribuição da idade como sendo uma distribuição normal. O que se espera é que aproximadamente $68 \%$ das observações estejam entre a média menos 1 desvio padrão e a média mais 1 desvio padrão, de forma que aproximadamente $16 \%$ das observações estejam na cauda inferior e aproximadamente 16\%, na cauda superior da distribuição (Fávero, Silva, Chan \& Belfiore, 2009).

O grupo dos estudantes mais velhos (média de -0,38) ficou composto por 75 respondentes, enquanto o grupo dos estudantes mais jovens (média de 0,06 ), com 61 . Ao verificar a diferença de médias, constatou-se uma diferença de 0,45 (considerando a componente principal) em favor dos estudantes mais jovens. Todavia, ao proceder-se ao Teste $t$ Student, essa diferença não foi estatisticamente significativa ( $\mathrm{p}=0,3909)$, o que levou à rejeição da segunda hipótese da pesquisa. Portanto, não se pode afirmar que existam diferenças entre a valorização que estudantes mais velhos e mais novos atribuem às variáveis internas (acessibilidade às instalações, custo, sustentabilidade financeira da instituição e financiamento de equipamentos).

Os resultados encontrados para essa hipótese foram diferentes dos que Vieira (2009) relatou. A autora supracitada encontrou diferença estatisticamente significativa entre as médias atribuídas às variáveis pelos estudantes, com idade média de 30 anos e o grupo de professores, com idade média de 47 anos.

A terceira e a quarta hipóteses da pesquisa referem-se à flexibilidade que um curso de $\mathrm{EaD}$ disponibiliza aos estudantes, na medida em que estes podem frequentá-lo de qualquer lugar, sem necessidade de deslocamentos frequentes aos polos de ensino, quando estes não estão sediados na própria cidade do estudante. Assim, acreditava-se que a variável acessibilidade ao polo fosse ter pouca importância para os estudantes, e uma importância ainda menor para aqueles que residem na mesma cidade em que o polo de apoio presencial está situado. Daí a formulação das hipóteses como se segue:

- $\quad \mathbf{H}_{3}:$ Os estudantes atribuem menor grau de importância à acessibilidade ao polo de apoio presencial em comparação às demais variáveis.

- $\quad \mathbf{H}_{4}$ : Estudantes residentes na cidade onde se localiza o polo de apoio presencial atribuem menor grau de importância a essa variável quando comparados aos outros estudantes.

Em relação à terceira hipótese, constatou-se que a variável acessibilidade ao polo de apoio teve grau de importância média de 8,5, o que tornou essa variável a $10^{a}$ mais importante para os estudantes. Por essa média, já se percebe que a referida variável teve uma importância maior que outras seis variáveis. O teste de diferença de médias indicou que a média das notas atribuídas à variável acessibilidade ao polo de apoio apresentou-se maior que a média da nota atribuída às variáveis contato com professor $(M=8,2, p$-value $=0,0435)$, pessoal técnico-administrativo ( $M=8,2, p$-value $=0,0353)$, participação dos colegas $(M=7,9, p$-value $=0,0001)$, interação entre estudantes $(M=7,6, p$-value $=0,0000)$ e financiamento de equipamentos $(M=7,3$, $p$-value $=0,0000)$, com nível de significância a 0,05 . Para as demais variáveis, não foram encontradas diferenças significativas entre as médias das notas atribuídas.

Desse modo, a terceira hipótese da pesquisa foi rejeitada, pois, considerando a média da variável acessibilidade ao polo de apoio, percebeu-se que a essa variável foi atribuído um grau de importância maior que as outras seis variáveis, diferença confirmada pelo Teste $t$ de Student para cinco delas (Tabela 3).

Finalmente, para se testar a quarta hipótese, os estudantes foram divididos em dois grupos: aqueles que residiam na mesma cidade do polo de apoio (153 estudantes) e aqueles que residiam em cidade diferente (201). A média de cada grupo foi de 8,4, para os respondentes residentes na mesma cidade onde se localizava o polo de apoio e 8,5 , para o grupo não residente. $O$ teste de diferença de médias indicou não haver diferença significativa entre as médias dos dois grupos de estudantes $(p=0,5088)$. Assim sendo, não 
foi possível confirmar a hipótese de que existam diferenças entre o grau de importância atribuído à variável acessibilidade pelos estudantes residentes nas cidades onde se localizam o polo de apoio presencial e por aqueles que residem em outra cidade, ocasionando a rejeição da quarta hipótese.

Tabela 3

Diferença do grau de importância para a variável acessibilidade

\begin{tabular}{|c|c|c|}
\hline Variável & Diferença & Média \\
\hline Flexibilidade & 0,7 & 1,0000 \\
\hline Corpo docente & 0,6 & 1,0000 \\
\hline Custo & 0,6 & 1,0000 \\
\hline Currículo & 0,5 & 1,0000 \\
\hline Metodologias pedagógicas utilizadas & 0,4 & 0,9997 \\
\hline Tutores & 0,4 & 0,9991 \\
\hline Material didático & 0,4 & 0,9995 \\
\hline Uso TIC & 0,3 & 0,9974 \\
\hline Sustentabilidade financeira & 0,1 & 0,7868 \\
\hline Atividades & $-0,1$ & 0,3102 \\
\hline Contato com professores & $-0,3^{*}$ & 0,0435 \\
\hline Pessoal técnico-administrativo & $-0,3^{*}$ & 0,0353 \\
\hline Participação dos colegas & $-0,6 *$ & 0,0001 \\
\hline Interação entre estudantes & $-0,9 *$ & 0,0000 \\
\hline Financiamento de equipamentos & $-1,2^{*}$ & 0,0000 \\
\hline
\end{tabular}

Esperava-se que os estudantes que não precisavam deslocar-se de sua cidade para frequentar as aulas presenciais dos cursos $\mathrm{EaD}$ atribuíssem um grau de importância menor à variável acessibilidade do que aqueles que não precisavam. Essa expectativa foi gerada por considerar-se que, para o primeiro grupo, o custo e o tempo gastos seriam consideravelmente menores e, portanto, não seria dispendioso participar dos encontros presenciais que eventualmente ocorrem.

Todavia, o que se constatou foi o contrário: a acessibilidade é fator relativamente importante para os respondentes de uma forma geral, o que parece estar relacionado com os comentários feitos pelos estudantes, que em sua maioria consideravam penoso ir aos encontros presenciais, mesmo estes ocorrendo com pouca frequência. O que se percebeu foi que, para os respondentes, os cursos a distância não deveriam ter encontros presenciais, já que eles consideraram que a flexibilidade que um curso desse tipo oferece não deveria exigir a presença física, apenas virtual. Assim, é possível inferir que, para os estudantes, a flexibilidade dos cursos $\mathrm{EaD}$ está associada à não existência de encontros presenciais, portanto exigir sua presença, mesmo que eventual, é para eles algo que requer um alto esforço.

\section{Conclusão}

A avaliação de curso é uma metodologia que permite aos interessados ter uma dimensão real sobre as variáveis que influenciam a qualidade. Scriven (1991) desenvolveu um método que objetiva avaliar os cursos na perspectiva do principal usuário, segundo o autor: o estudante. O método desenvolvido possibilita que a avaliação do curso seja feita pelos estudantes, facultando aos interessados visualizar deficiências e identificar as variáveis que influenciam a escolha do curso. 
Partindo da teoria de Scriven (1991), o objetivo geral desta pesquisa foi identificar e analisar o grau de importância atribuído por estudantes brasileiros às variáveis que os influenciam nas escolhas por cursos de pós-graduação lato sensu a distância na área de negócios. Tendo por base o arcabouço teórico utilizado, identificou-se que 16 variáveis apresentavam-se como possíveis determinantes na escolha dos estudantes. Assim, por meio da aplicação de um questionário, constatou-se que, para uma amostra de 354 estudantes de diferentes localidades brasileiras, essas variáveis têm significativo poder de influência. Chegou-se a tal conclusão ao verificar-se que a variável com menor poder de influência sobre os estudantes obteve um escore de $73 \%$ do máximo possível.

Considerando os resultados da pesquisa, as 16 variáveis escalonadas em ordem decrescente de acordo com o grau de importância atribuído pelos estudantes foram: flexibilidade, corpo docente, custo, currículo, metodologias pedagógicas utilizadas, tutores, material didático, uso de tecnologia de informação e comunicação de ponta, sustentabilidade financeira da instituição, acessibilidade às instalações, atividades, contato com professores, pessoal técnico administrativo, participação dos colegas, interação entre os estudantes e financiamento de equipamentos.

Observou-se pelos dados da pesquisa, que 4 variáveis tiveram média da nota acima de 9: flexibilidade, corpo docente, custo e currículo. Esse resultado evidencia que a possibilidade de poder estruturar o curso conforme suas disponibilidades de tempo é fundamental para os estudantes. Mas dispor de um corpo docente capacitado e de um currículo que seja adequado a sua situação pedagógica também é importante. Portanto, não se deve imaginar que nessa modalidade de ensino o impacto do trabalho do professor e o suporte pedagógico possam ser minimizados. Ao contrário, nos cursos a distância as funções dos docentes são expandidas, o que requer qualificações que não são exigidas de professores em cursos presenciais. Sobre a variável custo, destaca-se que ela é apontada por alguns autores como essencial na decisão dos estudantes em razão de os cursos $\mathrm{EaD}$ serem frequentemente mais baratos que os cursos presenciais.

Foram encontradas evidências que para as mulheres da amostra, as variáveis internas analisadas, são mais importantes que as externas em comparação com as médias das notas atribuídas pelos homens $\left(\mathrm{H}_{1}\right)$. Constatou-se, ainda, não haver diferença estatística significativa entre as notas atribuídas pelos estudantes mais velhos e pelos mais novos para as variáveis externas ou internas $\left(\mathrm{H}_{2}\right)$; e que a localização do polo de apoio deve ser considerado como fator importante na decisão dos estudantes, sem haver distinção entre aqueles que residem na mesma cidade do polo ou em outra cidade $\left(\mathrm{H}_{3}\right.$ e $\left.\mathrm{H}_{4}\right)$.

Por fim, sugere-se que futuros estudos sejam desenvolvidos de modo a identificar as necessidades pedagógicas dos estudantes, a partir de uma perspectiva deste como um agente não autônomo, ou seja, com necessidades maiores que as do estudante de cursos presencial, demandando uma estrutura didática de ensino que vai além do material didático e que o curso precisa oferecer. Sugere-se, ainda, pesquisas sobre a evasão dos estudantes de cursos $\mathrm{EaD}$, buscando evidências não só sobre a frequência desse evento, mas também sobre suas causas.

\section{Referências}

Ad Hamid, N. R. (2006). An Assessment of the Internet's Potential in Enhancing Consumer Relationships. Thesis (Doctor of Philosophy). Victoria University of Technology. Melbourne.

Bailey, S. (1997). Household Decision Making: Relative Influence of Husbands and Wives in the 1990's. Thesis (Masters of Management Studies School of Business). Faculty of Graduate Studies and Research of Carleton University. Ottawa.

Belloni, M. L. (2009). Educação a distância. Campinas: Autores Associados.

Bolliger, D. U. \& Wasilik, O. (2009). Factors Influencing Faculty Satisfaction with On-line Teaching and Learning in Higher Education. Distance Education, 30(1), 103-116. 
Brandão, H. P. (2009). Aprendizagem, contexto, competência e desempenho: um estudo multinivel. Tese (Doutorado em Psicologia Social, do Trabalho e das Organizações) - Programa de Pós-Graduação em Psicologia Social, do Trabalho e das Organizações da Universidade de Brasília, Brasília.

Burma, S. (2007). Art Education Faculty and Administrators Experiences with and Perceptions of Distance Education: A Mixed Methods Study. Dissertation (Doctor of Philosophy) - Graduate School of The Ohio State University, Ohio.

Burt, S. (2000). The Strategic Role of Retail Brands in British Grocery Retailing. European Journal of Marketing, 34(8), p.875-890.

Carr-Chellman, A. \& Duchastel, P. (2000). The Ideal On-line Course. British Journal of Educational Technology, 31(3), p. 145-158.

Carvalho, C. G. (2007). Satisfação dos consumidores de terceira idade nos meios de hospedagem de Balneário Camboriú/SC. Dissertação (Mestrado em Administração) - Centro de Educação de Biguaçu, Universidade do Vale do Itajái, Biguaçu.

Comarella, R. L. (2009). Educação superior a distância: evasão discente. Dissertação (Mestre em Engenharia e Gestão do Conhecimento) - Programa de Pós-Graduação em Engenharia e Gestão do Conhecimento, Universidade Federal de Santa Catarina, Florianópolis.

Cornachione Júnior, E. B. (2004). Tecnologia da educação e cursos de Ciências Contábeis: modelos colaborativos virtuais. Tese (Livre-Docência) - Faculdade de Economia, Administração e Contabilidade, Universidade de São Paulo, São Paulo.

Davok, D. F. (2006). Modelo de meta-avaliação de processos de avaliação da qualidade de cursos de graduação. Tese (Doutorado em Engenharia de Produção) - Programa de Pós-Graduação em Engenharia de Produção, Universidade Federal de Santa Catarina, Florianópolis.

Decreto 5.622, de 19 de dezembro de 2005. (2005). Regulamenta o art. 80 da Lei no 9.394, de 20 de dezembro de 1996, que estabelece as diretrizes e bases da educação nacional.

Duarte, S. V. \& Furtado, M. S. V. (2002). Manual para elaboração de monografias e projetos de pesquisas. (3. ed.) Montes Claros: Unimontes.

Fávero, L. P. L., Silva, F. L. da S., Chan, B. L. \& Belfiore, P. P. (2009). Análise de Dados: Modelagem Multivariada para Tomada de Decisões. São Paulo: Saraiva.

Ford, J. B., Joseph, M. \& Joseph, B. (1999). Importance-performance Analysis as a Strategic Tool for Service Marketers: The Case of Service Quality Perceptions of Business Students in New Zealand and the USA. The Journal of Services Marketing, 13(2), p. 171-186.

Gallifa, J.\& Batallé, P. (2010). Student perceptions of service quality in a multi-campus higher education system in Spain. Quality Assurance in Education, 18(2), p.156 - 170

Gall, M. D., Gall, J. P. \& Borg, W. R. (2007). Educational Research: An Introduction. 8. ed. Boston: Pearson Education.

Garrison, R. (2000). Theoretical Challenges for Distance Education in the $21^{\text {st }}$ Century: A Shift from Structural to Transactional Issues..International Review of Research in Open and Distance Learning, 1(1), p.1-17.

Goecking, O. H. P. (2006). Comparação de teorias da ação para explicar interações comportamentais e comportamentos reais correspondentes. Dissertação (Mestrado em Administração) - Centro de Pós-Graduação e Pesquisa em Administração do Departamento de Ciências Administrativas, Faculdade de Ciências Econômicas, Universidade Federal de Minas Gerais, Belo Horizonte. 
Granito, R. A. N. (2008). Educação a distância e estilos de aprendizagem: elaboração de um protocolo de qualidade para ambientes virtuais de ensino. Dissertação (Mestrado em Administração Organizacional) - Programa de Pós-Graduação em Administração de Organizações, Faculdade de Economia, Administração e Contabilidade, Universidade de São Paulo, Ribeirão Preto.

Henckell, M. M. (2007). Evaluating Distance Education: The Student Perspective. Dissertation (Doctor of Education) - The Faculty of the Graduate School, University of Missouri, Columbia.

Hashimoto, K. (2009). An Evaluation Framework for Educational Reform Projects for Teacher Quality Improvement in Developing Countries: A Case Study of Egyptian Education Reform. Doctor of Philosophy. School of Professional \& Learning Studies Faculty of Education Queensland University of Technology. Brisbane.

Instituto Brasileiro de Geografia e Estatística (IBGE). (2011). Resultados preliminares do universo do Censo Demográfico 2010. Recuperado em 11 julho, 2011 de http://www.ibge.gov.br/series_estatisticas/.

Instituo Nacional de Estudos e Pesquisas (INEP). (2009). Sistema Nacional de Avaliação da Educação Superior: da concepção à regulamentação. (5. ed.) Brasília: Inep.

. (2010). Censo da educação superior. Recuperado em 10 março, 2010 de http://www.inep.gov.br/superior/censosuperior/default.asp.

Johnston, J., Killion, J. \& Oomen, J. (2005). Student Satisfaction in the Virtual Classroom. The Internet Journal of Allied Health Sciences and Practice, 3(2), p. 1-7.

Kiesler, S. \& Sproull, L. S. (1986). Response Effects in the Electronic Survey. Public Opinion Quarterly, 50(3), p. 402-413.

LeBlanc, G. \& Nguyen, N. (1997). Searching for Excellence in Business Education: An Exploratory Study of Customer Impressions of Service Quality. International Journal of Educational Management, 11(2), p. $72-79$.

Lei no 9.394, de 20 de dezembro de 1996. (1996). Estabelece as Diretrizes e Bases da Educação Nacional.

Luzzi, D. A. (2007). O papel da educação a distância na mudança de paradigma educativo: da visão dicotômica ao continuum educativo. Tese (Doutorado em Educação) - Programa de Pós-Graduação em Educação, Faculdade de Educação, Universidade de São Paulo, São Paulo.

Mantovani, D. M. N. \& Gouvêa, M. A. (2010). Sistemas de informação na educação: o uso de uma plataforma de educação a distância no ensino de estatística plicada à administração. $7^{\circ}$ International Conference on Information Systems and Technology Management (CONTECSI). Anais. São Paulo.

McGorry, S. Y. (2003). Measuring Quality in On-line Programs. The Internet and Higher Education, 6, p. 159-177.

MEC - Ministério da Educação. (2007). Referenciais de Qualidade para Educação Superior a Distância. Brasília: MEC.

(2010). Instituições de Educação Superior e Cursos Cadastrados. Recuperado em 04 maio, 2010 de http://emec.mec.gov.br/.

. (2013). Instituições de Educação Superior e Cursos Cadastrados. Recuperado em 27 dezembro, 2013 de http://emec.mec.gov.br/.

Michel, L. M. (2010). Value-added Poultry Product Development: A Consumer Driven Approach. Thesis (Master of Science) - Department of Agricultural, Food, and Nutritional Science of the Faculty of Graduate Studies and Research of the University of Alberta. Alberta.

Middendorf, B. J. (2009). Evaluating Department Chairs' Effectiveness Using Faculty Ratings. Dissertation (Doctor of Philosophy) - Department of Curriculum and Instruction College of Education, Kansas State University, Manhattan. 
Mingoti, S. A. (2005). Análise de dados através de métodos de estatística multivariada: uma abordagem aplicada. Belo Horizonte: Editora UFMG.

Motta, S. L. S. (2009). Estudo sobre segmentação de mercado consumidor por atitude e atributos ecológicos de produtos. Tese (Doutorado em Administração) - Departamento de Administração, Faculdade de Economia, Administração e Contabilidade, Universidade de São Paulo, São Paulo.

Nichols, M. (2010). Student Perceptions of Support Services and the Influence of Targeted Interventions on Retention in Distance Education. Distance Education, 31(1), 93-113.

Oldfield, B. M. \& Baron, S. (2000). Student Perceptions of Service Quality in a UK University Business and Management Faculty. Quality Assurance in Education, 8(2), 85-95.

Patton, M. Q. (2008). Utilization-focused Evaluation. Evaluation in Education and Human Services. (4. ed.) Sage Publications: Thousand Oaks.

Penterich, E. (2009). Competências organizacionais para a oferta da educação a distância no ensino superior: um estudo descritivo-exploratório de IES brasileiras credenciadas pelo MEC. Tese (Doutorado em Administração) - Programa de Doutorado em Administração do Departamento de Administração, Faculdade de Economia, Administração e Contabilidade, Universidade de São Paulo, São Paulo.

Piercy, N. (2013). Online service quality: Content and process of analysis. Journal of Marketing Management. 46. doi: 10.1080/0267257X.2013.839571

Poth, C. A. N. (2008). Promoting Evaluation Use Within Dynamic Organizations: a case study examining evaluator behavior. Thesis (Doctor of Philosophy) - Faculty of Education, Queen's University, Ontario.

Ruas, R. \& Comini, G. M. (2007). Aprendizagem e desenvolvimento de competências: articulando teoria e prática em programa de pós-graduação em formação gerencial. Cadernos EBAPE.BR, 5, Edição Especial.

Sabir, R. I.; Ahmad, W.; Ashraf, R. U. \& Ahmad, N. (2013). Factor Affecting University and Course Choice: a comparison of undergraduate engineering and business students in Central Punjab, Pakistan. Journal of Basic and Applied Scientific Research. 3(10), 298-305.

Sampieri, R. H., Collado, C. F. \& Lucio P. B. (2006). Metodologia de pesquisa. 3. ed. São Paulo: McGraw-Hill.

Schein, M., Perin, M. G. \& Sampaio, C. H. (2009). O comportamento da compra de serviços de turismo na terceira idade. Revista Turismo Visão e Ação, 11(3), 341-357.

Scriven, M. (1991). Evaluation Thesaurus. (4. ed.) California: Sage Publications, 1991.

Serviço de Apoio às Micro e Pequenas Empresa de São Paulo (Sebrae-SP). (2010). 12 anos de monitoramento da sobrevivência e mortalidade de empresas. São Paulo: Sebrae-SP.

Silva, L. A. da. (2009). Atitude do consumidor em relação às marcas próprias de supermercados: um estudo exploratório. Dissertação (Mestrado em Administração de Organizações) - Faculdade de Economia, Administração e Contabilidade, Universidade de São Paulo, Ribeirão Preto.

Unesco - United Nations Educational, Scientific and Cultural Organization. (2002). Open and Distance Learning: Trends, Policy and Strategy Considerations. Paris: Division of Higher Education.

Veale, R. (2007). Investigating the Simultaneous Influence of Intrinsic and Extrinsic Cues: An Examination of the Interaction between Country of Origin, Price and Select Sensory Variables. Thesis (Doctor of Philosophy) - The University of Adelaide, Adelaide.

Vieira, S. S. da C. (2009). Avaliação de programas de educação continuada: análise da percepção do aluno e do seu modelo de decisão para escolha de programas de especialização para executivos no Brasil. Tese (Doutorado em Ciências Contábeis) - Departamento de Contabilidade e Atuária, Faculdade de Economia, Administração e Contabilidade, Universidade de São Paulo, São Paulo. 